\title{
Examining the asymmetric effects of fiscal policy instruments on environmental quality in Asian economies
}

\author{
Sana Ullah ${ }^{1}$ (D) Muhammad Tariq Majeed ${ }^{1} \cdot$ Muhammad Zubair Chishti $^{1}$
}

Received: 1 May 2020 / Accepted: 22 June 2020 / Published online: 4 July 2020

(C) Springer-Verlag GmbH Germany, part of Springer Nature 2020

\begin{abstract}
Empirical studies pertaining to the effects of fiscal policy instruments on environmental quality have provided mixed evidence. We consider the asymmetric effects of fiscal policy instruments on environmental quality for the top ten Asian carbon emitters over the period 1981-2018. We go beyond the literature and claim that the effects could be asymmetric. More specifically, we found that a positive shock in government expenditure will worsen environmental quality in Malaysia, UAE, Thailand, Indonesia, Turkey, Iran, India, and China, and improve it in Japan. On the other hand, we found that cutting government expenditure will improve environmental quality in these economies and will worsen only in Japan. Moreover, a higher government income tax revenue uniquely increases the government's spending that increases the carbon emissions in Malaysia, UAE, Thailand, Indonesia, Turkey, Iran, India, and China, and decrease in Japan. The negative shock of government revenue has adverse results on carbon emissions in these economies. However, short-run asymmetric effects translate to long-run effects in most Asian economies.
\end{abstract}

Keywords Fiscal policy $\cdot$ Environmental pollution $\cdot$ Asymmetric ARDL $\cdot$ Asia economies

\section{Introduction}

The dynamic relationships between environmental quality, energy use, and economic growth have attracted substantial attention from scholars during the last few decades. The tradeoff between environmental quality and economic growth is a global dilemma. Since the beginning of the industrial revolution from about 1760s, global economic growth has increased substantially at the cost of environmental degradation. The basic reason behind environmental loss is the use of conventional energy sources such as coal and fossil fuels in the production processes. Therefore, economic growth,

Responsible editor: Nicholas Apergis

Sana Ullah

sana_ullah133@yahoo.com

Muhammad Tariq Majeed

tariq@qau.edu.pk

Muhammad Zubair Chishti

chishtimz9@gmail.com

1 School of Economics, Quaid-i-Azam University, Islamabad, Pakistan energy use, and environmental degradation show an amalgamation of triumvirate complicated structures - trilemma.

The relationship of fiscal instruments with environmental quality has attracted the attention of the environmental and energy economists in recent years. The studies, however, are fairly limited in the existing empirical literature. The fiscal role for environmental quality can be both amplifying and mitigating $\mathrm{CO}_{2}$ emissions. Few studies have considered government spending as a fiscal instrument to control the environmental quality (Frederik and Lundström 2001; Bernauer and Koubi 2006; López et al., 2011; Halkos and Paizanos 2013, 2016). López et al. (2011) suggested four channels through which fiscal spending can influence pollution concentrations in the atmosphere namely "scale, composition, technique, and income" impacts. First, the scale effect refers to the pressure on the environment because of high economic growth. Second, the composition effect refers to the change in the composition of inputs for production. Physical capitalintensive inputs are switched with human capital-intensive inputs, which are less polluting. Third, the technique effect implies acquiring efficient laborer work as a result of improved work routines. Fourth, income effect indicates an increasing priority and the need for a better environment because of high-income status. In another study, Chaturvedi 
et al. (2014) provided a theoretical discussion on environmental fiscal reforms (EFR) in the context of India. They concluded, "EFR can lead to environmental improvement more efficiently and cost-effectively than traditional regulation."

In an earlier study, Frederik and Lundström (2001) explored the effects of economic freedom and government size on pollution using the data for high- and low-income countries. They found economic freedom increases emissions while government spending decreases emissions. Bernauer and Koubi (2006) also explored the impact of government size on the quality of the environment using a sample of 42 countries from 1971 to 1996 . They found out that government spending lowers pollution only in the case when the demand for public goods is entertained. Halkos and Paizanos (2013) investigated the effect of government expenditures on environmental quality employing a panel data set of 77 economies from 1980 to 2000. The results demonstrated that government spending has an insignificant impact on $\mathrm{CO}_{2}$ emissions while it has a significant and negative effect on $\mathrm{SO}_{2}$ emissions. They also estimated the indirect effects of pollutants on government expenditures through income levels. The results revealed that the effect of $\mathrm{SO}_{2}$ changes from negative to positive as income increases. The empirical studies such as Lopez and Palacios (2010), Halkos and Paizanos (2016), and Katircioglu and Katircioglu (2018) have considered government spending and revenues as fiscal policy instruments in their empirical model. One major limitation of these studies is that they neglected the asymmetric relationships between fiscal policy instruments and $\mathrm{CO}_{2}$ emissions.

Recently, Gerlagh et al. (2018) explored the role of fiscal policy in controlling carbon emissions for 15 European Union (EU) countries in the context of new passenger cars over the time span 2001-2010. They analyzed the impact of fiscal policy using a measure of the vehicle registration and annual road tax levels. Their findings suggest that registration taxes lowers carbon emissions. However, the findings of their study cannot be generalized as they are limited to the car industry. The empirical literature has neglected the dynamic relationships between fiscal policy instruments and $\mathrm{CO}_{2}$ emissions by incorporating both negative and positive components of fiscal policy instruments. Moreover, the evidence for the Asian region is overlooked in the existing literature.

Similarly, in another recent study, Katircioglu and Katircioglu (2018) tested the importance of fiscal policy for environmental quality for Turkey over the period 1960-2013. The empirical results, based on the linear ARDL model, reveal that fiscal aggregates help to lower carbon emissions implying that fiscal policy has a significant role in managing environmental quality in the context of Turkey. Yuelan et al. (2019) explored the nexus of fiscal policy instruments and environmental degradation for China over the period 1980-2016. The empirical results of their study showed that fiscal policy instruments significantly increase environmental degradation in the long run. That is, expansionary fiscal policy compromises the environmental quality in the context of China. One limitation of these studies is that they assume a symmetric relationship between fiscal policy instruments and environmental quality. Moreover, the findings of these studies cannot be generalized at a regional level as they are limited to country-specific experiences.

Asia is a rapidly growing region and millions of poor have been lifted from the poverty traps. However, this growth is coming at the cost of environmental disruption. Energy use, consumption of natural resources, and coupled emissions are also displaying similar trajectories as of economic growth. Oil consumption has increased by $92 \%$ between the years (19902010), and it is expected to increase by $44 \%$ from 2010 to 2030 (Asian Development Bank (ADB), 2011). According to an estimate, the coal could account for $50-70 \%$ of new power supply in Asia (International Energy Agency, 2012). Asia as a region is responsible for about $40 \%$ of global greenhouse gas emissions, which can escalate up to $50 \%$ if sustainable measures are not adopted (Dulal et al. 2015). Thus, Asian economies are increasingly getting trapped in pollutionconcentrated development routes.

The dynamic relationships of economic growth, fiscal policy instruments, and environmental quality are neglected in the case of Asia in general and top polluting Asian economies in particular. There is the only study that explores the scope of fiscal policy instruments to manage the environmental quality of Asian countries. Dulal et al. (2015) provided an exploratory analysis of fiscal policy and environmental quality. The study provided facts about environmental changes in the region and concludes that the region is increasingly getting locked in carob-intensive development paths.

Moreover, Dulal et al. (2015) explored the scope of fiscal policy in helping the region to avoid the carbon-intensive paths and conclude that fiscal policy has a greater scope in the region, particularly carbon tax policy and taxation of the use of natural resources. However, fiscal policy instruments are not adapted to the required extent. Dulal et al. (2015) emphasize the need for fiscal policy instruments to manage the environmental quality of the region. However, this study is qualitative in its nature and does not provide any firm empirical evidence. Therefore, the scope for empirical studies for the region is the need of the present time. Furthermore, the findings of these studies, however, neither certain nor can be generalized. These studies provide evidence based on a single country-specific experience. Moreover, these studies assume a linear relationship between fiscal policy instruments and environmental quality ignoring hidden nonlinear relationships. It is not necessary that both positive and negative shocks in fiscal policy instruments have linear effects on environmental quality. Therefore, it is important to estimate the asymmetric effects of changes in fiscal policy instruments on 
environmental quality. Our study deviates from the entire empirical literature by arguing that the impacts of fiscal policy instruments on environmental quality could be asymmetric, therefore we applied the NARDL methodology in this analysis.

Based on the findings of the aforementioned studies, it can be inferred that fiscal policy has heterogeneous effects on environmental quality depending upon the kinds of pollutants and geographical locations and income groups of the countries. Thus, more empirical research is required for a better understanding of the fiscal policy and environment nexus. The present study aims to explore the dynamic relationships between fiscal policy instruments and $\mathrm{CO}_{2}$ emissions for the top ten pollution emitting Asian countries over the time span of 1981-2018. The scope of the present study is wider as few studies are available in the literature, which focuses on fiscal policy and environment. The studies generally focus on government spending aspect of the fiscal policy; therefore, the studies with the focus on both government spending and revenue instruments are quite limited. The problem of ecological disruption as a result of GHG emissions can only be resolved with a suitable fiscal rejoinder.

This study contributes to the literature in the following ways: First, this study controls the twin impact of both fiscal policy instruments namely government expenditures and government revenues. Second, we use a novel approach of estimation that is asymmetric effects of fiscal policy instruments on environmental quality. Third, this study provides an analysis of the top ten $\mathrm{CO}_{2}$ emitting Asian countries.

The present study focuses exclusively on Malaysia, United Arab Emirates, Thailand, Indonesia, Turkey, Iran, Saudi Arabia, Japan, India, and China owing to the unique characteristics of these countries. These countries are the top ten carbon emitters from Asia and they are major sources of global $\mathrm{CO}_{2}$ emissions. We consider these countries as an appropriate sample based on not only their significant share in global emissions but also the absolute size of their $\mathrm{CO}_{2}$ emissions. Therefore, these countries have a strong impact on world energy demand and expenditures and global ecological balance. Thus, it is imperative to provide separate empirical analysis for the top ten emitting countries from Asia. In the existing literature, the role of fiscal policy instruments, particularly the twin effect of government expenditures and revenue, is less focused. Moreover, the past literature has used symmetric modeling methods for empirical analysis providing conflicting results, whereas asymmetric modeling provides more comprehensive and authoritative results. Thus, it is important to explore the asymmetric effects of fiscal policy instruments on environmental quality. This research provides a robust empirical analysis of fiscal policy instruments and environmental pollution using time series annual data of the top ten pollution emitting courtiers from 1981 to 2018.
The rest of the study is organized as follows: A discussion on methodology and model is provided in "Model and methodology." Empirical results and discussion are presented in "Empirical results and discussion.". Finally, "Conclusion and policy implications" concludes the study and offers policy implications.

\section{Model and methodology}

Thus, to examine the effects of fiscal policy instruments on environmental quality, this study considers the following proposed econometric models: Yuelan et al. (2019) followed a similar reduced form the model as sketched by Equation 1:

$\mathrm{CO}_{2, \mathrm{t}}=\sigma_{0}+\sigma_{1} \operatorname{Gexp}_{\mathrm{t}}+\sigma_{2} \mathrm{Grev}_{\mathrm{t}}+\sigma_{3} \mathrm{EG}_{\mathrm{t}}+\varepsilon_{\mathrm{t}}$

where $\mathrm{CO}_{2 \mathrm{t}}$ is a measure of the carbon emissions in Pakistan in the share of world emissions. Gexp is measured $_{t}$ by government expenditure (\% GDP), $\mathrm{Grev}_{t}$ is measured by government revenue (\% GDP), and $\mathrm{EG}_{t}$ is the economic growth of Pakistan. The next phase in our model is to comprise short-run effects into the equation (1). In order to obtain short- and long-run estimates in a single step, we also follow Pesaran et al. (2001) ARDL approach to the error-correction framework and cointegration as follows:

$$
\begin{aligned}
\Delta \mathrm{CO}_{2, \mathrm{t}}= & \sigma_{0}+\sum_{i=1}^{\mathrm{n} 1} \psi_{\mathrm{i}} \Delta \mathrm{CO}_{2, t-i}+\sum_{i=0}^{\mathrm{n} 2} \mu_{i} \Delta \operatorname{Gexp}_{t-\mathrm{i}} \\
& +\sum_{i=0}^{\mathrm{n} 3} \mathrm{v}_{i} \Delta \operatorname{Grev}_{t-i}+\sum_{i=0}^{\mathrm{n} 4} \phi_{\mathrm{i}} \mathrm{EG}_{t-i}+\sigma_{1} \mathrm{CO}_{2, t-1} \\
& +\sigma_{2} \operatorname{Gexp}_{t-1}+\sigma_{3} \operatorname{Grev}_{t-1}+\sigma_{4} \mathrm{EG}_{t-1} \\
& +\varepsilon_{t}
\end{aligned}
$$

The specification well-defined in equation (2) has an additional benefit over a standard error-correction model in that it allows us short- and long-run effects in a single-step OLS method or others. Once again, coefficients attached to firstdifferenced exogenous variables reveal short run and estimates of $\sigma_{2}-\sigma_{4}$ normalized on $\sigma_{1}$ reveal the long-run effects, see Bahmani-Oskooee et al. (2019). Certainly, for the longrun estimates to be important, cointegration among the macro variables must be established. Therefore, Narayan (2005) endorses the usage of the $F$ statistics to found a joint significance of the linear model and has presented a new set of tabulated critical values that are valid for small samples. However, the main fundamental hypothesis in equation (1) or equation (2) is that the government expenditure and government revenue have symmetric/linear effects on the environments. In other short words, the environment's pollution is assumed to have a 
similar elasticity with respect to a positive and negative shock of fiscal policy instruments. We follow the Shin et al. (2014) methodology of asymmetry in the environmental relationship. Next, we generate the idea of partial sum and generate four new time series as follows:

$$
\begin{aligned}
& \operatorname{Gexp}^{+}{ }_{t}=\sum_{n=1}^{\mathrm{t}} \Delta \operatorname{Gexp}^{+}{ }_{t}=\sum_{n=1}^{\mathrm{t}} \max \left(\Delta \operatorname{Gexp}^{+}, 0\right) \\
& \operatorname{Gexp}_{t}{ }_{t}=\sum_{n=1}^{\mathrm{t}} \Delta \operatorname{Gexp}^{-}=\sum_{t=1}^{\mathrm{t}} \min \left(\Delta \operatorname{Gexp}^{-}, 0\right) \\
& \operatorname{Grev}^{+}{ }_{t}=\sum_{n=1}^{\mathrm{t}} \Delta \operatorname{Grev}^{+}{ }_{t}=\sum_{n=1}^{\mathrm{t}} \max \left(\Delta \operatorname{Grev}^{+}{ }_{t}, 0\right) \\
& \operatorname{Grev}^{-}=\sum_{n=1}^{\mathrm{t}} \Delta \operatorname{Grev}^{-}{ }_{t}=\sum_{n=1}^{\mathrm{t}} \min \left(\Delta \operatorname{Grev}^{-}{ }_{t}, 0\right)
\end{aligned}
$$

Here, $\operatorname{Gexp}^{+}{ }_{t} / \operatorname{Grev}^{+}{ }_{t}$ is a two-time series of variables indicating the partial sum of the positive shocks. Similarly, Gexp ${ }_{t}^{-} / \mathrm{Grev}^{-}{ }_{t}$ signifies a time-series variable that only captures the partial sum of the negative shocks. For the asymmetric model, we replace government expenditure and government revenue in equation (2) with $\mathrm{Gexp}^{+} / \mathrm{Gexp}_{t}^{-}$and $\mathrm{Grev}^{+} / \mathrm{Grev}_{t}^{-}$and attain the following model specification:

$$
\begin{aligned}
\Delta \mathrm{CO}_{2, t}= & \sigma_{0}+\sum_{i=1}^{\mathrm{n} 1} \psi_{\mathrm{i}} \Delta \mathrm{CO}_{2, t-i}+\sum_{i=0}^{\mathrm{n} 2} \eta_{i} \Delta \mathrm{Gexp}^{+}{ }_{t-i} \\
& +\sum_{i=0}^{\mathrm{n} 3} v_{i} \Delta \operatorname{Gexp}^{-}{ }_{t-i}+\sum_{i=0}^{\mathrm{n} 4} \theta_{\mathrm{i}} \Delta \mathrm{Grev}^{+}{ }_{t-\mathrm{i}} \\
& +\sum_{i=0}^{\mathrm{n} 5} \mu_{\mathrm{i}} \Delta \mathrm{Grev}^{-}{ }_{t-i}+\sum_{i=0}^{\mathrm{n} 6} \phi_{\mathrm{i}} \mathrm{EG}_{t-i}+\sigma_{1} \mathrm{CO}_{2, t-1} \\
& +\sigma_{2} \operatorname{Gexp}^{+}{ }_{t-1}+\sigma_{3} \operatorname{Gexp}^{-}{ }_{t-1}+\sigma_{4} \mathrm{Grev}^{+}{ }_{t-1} \\
& +\sigma_{5} \mathrm{Grev}^{-}{ }_{t-1}+\sigma_{6} \mathrm{EG}_{t-1}+\varepsilon_{\mathrm{t}}
\end{aligned}
$$

Estimates of equation (7) propose an opportunity to examine asymmetries along several dimensions. Therefore, for instance, different estimated lag structures of $\mathrm{Gexp}_{t}^{+} / \mathrm{Grev}^{+}{ }_{t}$ and $\mathrm{Gexp}_{t}^{-} / \mathrm{Grev}^{-}{ }_{t}$ can shed light on the short-term asymmetries of the environmental pollution with respect to positive and negative shocks of fiscal policy instruments. Similarly, the differences in the estimates of $\mathrm{Gexp}_{t}^{+} / \mathrm{Grev}^{+}{ }_{t}$ and $\mathrm{Gexp}^{-} / \mathrm{Grev}^{-}$can notify us about the difference in the sign and size of the effects due to partial sum. Using the Wald statistics, the presence of short-run cumulative asymmetries can be confirmed by rejecting null hypotheses $\mathrm{H}_{0}: \Sigma \eta_{i}=\Sigma v_{i}$ and $\Sigma \theta_{i}=\Sigma \mu_{i}$. Finally, the long-run asymmetries of government expenditure and government revenue can be confirmed if the null hypotheses $\mathrm{H}_{0}:{ }^{\sigma_{2}{ }^{+}} / \sigma_{\sigma_{1}}{ }^{\sigma^{-}} / \sigma_{1}$ and $\sigma_{4}{ }^{+} / \sigma_{1}{ }^{\sigma_{5}}{ }^{-} / \sigma_{1}$ are nullified in favor of a disparity.

\section{Data description}

This study uses a dataset from 1981 to 2018 for the top ten carbon emitters from Asia regions, such as Malaysia, United Arab Emirates, Thailand, Indonesia, Turkey, Iran, Saudi Arabia, Japan, India, and China. Definitions of $\mathrm{CO}_{2}$, Gexp, Grev, and EG are given in Table 1 and all data attained from the World Bank (2020). In the study, all indicators are taken non-logarithmic form except the variable of $\mathrm{CO}_{2}$, while we take the data of $\mathrm{CO}_{2}$ in logarithmic form in our estimation, and while $\mathrm{CO}_{2}$, Gexp, Grev, and EG summary statistics are given in Table 2 for selected Asian countries. The statistics show that China is the highest carbon emitters with a value of $4,837,142 \mathrm{kt}$. While the UAE is $98,828 \mathrm{kt}$ of carbon pollution producing, which is the smallest in our sample. Moreover, $25.95 \%$ is the highest and $8.90 \%$ is the lowest mean value of Gexp of Saudi Arabia and Indonesia, respectively. Similarly, the mean values of Grev vary from 3.60 (UAE) to $37.62 \%$ (Saudi Arabia), which infers that Indonesia and UAE are at the lowest in Gexp and Grev. The statistic of EG shows that the minimum mean value (3.26\%) belongs to Iran and the maximum mean value $(9.56 \%)$ belongs to China in our sample.

\section{Empirical results and discussion}

We begin by using the ADF and PP unit root statistics to estimate the extent to which the time series are non-stationary. The results are recapped in Table 3 and outcomes show that dependent, independent, and control variables are a mixture of $I(0)$ and $I(1)$, and none of the variables are integrated $I(2)$. In Table 4, Zivot-Andrews (ZA) unit root statistics show that

Table 1 Variables description

\begin{tabular}{llll}
\hline Variables & Symbol & Definition & Data source \\
\hline Carbon dioxide emissions & $\mathrm{CO}_{2}$ & Carbon dioxide emissions (Kilotons) & World Bank \\
Government expenditures & Gexp & Government expenditure (\% of GDP) & World Bank \\
Government revenues & Grev & Government revenues (\% of GDP) & World Bank \\
GDP growth & EG & GDP growth (annual \%) & World Bank \\
\hline
\end{tabular}


Table 2 Descriptive statistics

\begin{tabular}{llllll}
\hline \multirow{2}{*}{ Malaysia } & & $\mathrm{CO}_{2}$ & Gexp & Grev & EG \\
& Mean & $132,192.4$ & 13.12 & 22.28 & 5.80 \\
UAE & Std. dev. & $73,094.78$ & 1.94 & 3.10 & 3.58 \\
& Mean & $98,828.23$ & 11.30 & 3.60 & 3.37 \\
Thailand & Std. dev. & $51,727.87$ & 2.29 & 1.91 & 5.81 \\
& Mean & $180,357.2$ & 13.34 & 17.69 & 5.18 \\
Indonesia & Std. dev. & $93,585.67$ & 2.28 & 1.79 & 3.90 \\
& Mean & 293,525 & 8.90 & 17.68 & 5.03 \\
Turkey & Std. dev. & $148,697.4$ & 1.41 & 2.86 & 3.40 \\
& Mean & $209,751.9$ & 12.01 & 20.63 & 4.75 \\
Iran & Std. dev. & $81,301.5$ & 2.29 & 6.88 & 4.18 \\
& Mean & $368,677.2$ & 12.66 & 20.92 & 3.26 \\
Saudi Arabia & Std. dev. & 173,959 & 2.62 & 4.40 & 6.76 \\
& Mean & $332,657.2$ & 25.95 & 37.62 & 2.10 \\
Japan & Std. dev. & $137,611.3$ & 4.55 & 9.53 & 7.66 \\
& Mean & $1,156,889$ & 16.81 & 11.71 & 1.93 \\
India & Std. dev. & $154,455.5$ & 2.38 & 1.18 & 2.27 \\
& Mean & $1,084,163$ & 10.88 & 12.27 & 6.15 \\
China & Std. dev. & $550,249.2$ & 0.65 & 0.80 & 1.91 \\
& Mean & $4,837,142$ & 14.01 & 9.47 & 9.56 \\
& Std. dev. & $2,851,622$ & 0.95 & 3.87 & 2.75 \\
\hline & & & & &
\end{tabular}

most of our indicators are stationary at the $I(1)$. ARDL methodology fulfills the combination of $I(0)$ and $I(1)$, but not $I(2)$; hence, we follow this approach. The next step is to decide the appropriate number of lags for our analysis. To that end, we have used the Akaike information criteria (AIC) and applied the maximum of four lags for the annual data in the case of each of our models. In NARDL methodology, we adopted the general-to-specific modeling approach.

Table 5 reports the estimates of the asymmetric ARDL technique. In Table 5, panel A exhibits that the short-run outcome, we infer that positive shocks in government expenditure carry the favorable effects on the environmental quality of 6 economies (Malaysia, UAE, Turkey, Saudi Arabia, Japan, and China) by decreasing the $\mathrm{CO}_{2}$. On the contrary, the remaining 4 economies, including Thailand, Indonesia, Iran, and India, have to endure climate degradation on account of the upward trend in government expenditures. Furthermore, the negative shocks of government expenditures affect the climate of Thailand, Indonesia, Iran, and India positively, while the environment of the remaining 6 economies negatively by decreasing and increasing pollution, respectively, except the economy of Malaysia.

Also, half of the selected economies, i.e., Malaysia, UAE, Saudi Arabia, Japan, and China get the environmental benefits, and the other half countries face the environmental deterioration, as the positive shocks in the collection of the government revenues tend to contract and expand the level of $\mathrm{CO}_{2}$ emissions, respectively. Besides, the negative shocks in government revenues have a significantly negative impact on pollution in the case of Thailand, Indonesia, Turkey, and India by reducing carbon dioxide. However, these shocks degrade the climate of UAE, Iran, Saudi Arabia, and Japan, except the Malaysian and Chinese economies that do not respond to the negative shocks. Interestingly, all the economies demonstrate the consensus on the unfriendly environmental effects of GDP growth on account of surging carbon emissions.

As for as the long-run asymmetric effects of modeled regressors, panel B confirms that positive shocks in government expenditures harm the environment of 8 out of 10 economies. It indicates that $1 \%$ increase in government expenditure tends to increase $\mathrm{CO}_{2}$ emissions by $0.172 \%$ in Malaysia, $0.231 \%$ in UAE, $0.307 \%$ in Thailand, $0.471 \%$ in Indonesia, $0.178 \%$ in Turkey, $0.093 \%$ in Iran, $0.366 \%$ in India, and $0.188 \%$ in China. These findings are in line with the results of Halkos and Paizanos (2016) and Yuelan et al. (2019) who noted the possible reason is that government expenditure of these economies are invested in such economic projects that consume the fossil fuel-based energy excessively which results in an enormous amount of carbon dioxide emissions. The possible reason is that government consumption improvs the physical infrastructure including roads, transportation, and housing societies that increase carbon pollution. This also implies that government consumption increases urbanization that is one of the sources of carbon pollution. Also, if government spending has a significant effect on energy consumption, then the current fiscal spending enhances economic activities necessarily harmful to the environment. The results also infer that government spending leads to domestic private consumption with the investment that also increases environmental pollution. Furthermore, the economy of Japan gets benefitted due to the upward trend of government expenditures as it diminishes the $\mathrm{CO}_{2}$ by $0.352 \%$. Possibly, the Japanese government prefers to invest in such economic projects in which the latest climate-friendly technology is deployed; consequently, the pollution ratio declines. This implies that Japanese consumption most on the human capital activities includes health and education sectors that are small emitters of carbon compared to physical capital infrastructure. Besides, the Saudi Arabian economy's response remains insignificant.

Conversely, the negative shocks in government expenditure carry an adverse impact on environmental pollution in the case of 7 out of 10 countries. It implies that a $1 \%$ decrease in government expenditure leads to a reduction in the ratio of $\mathrm{CO}_{2}$ by $0.062 \%$ in Malaysia, $0.181 \%$ in UAE, $0.092 \%$ in Thailand, $0.280 \%$ in Indonesia, $0.042 \%$ in Turkey, $0.031 \%$ in Iran, and $0.178 \%$ in India. Moreover, this finding is also consistent with Katircioglu and Katircioglu (2018) and Chan (2020), who found that a contractionary fiscal policy could decrease environmental pollution. Contractionary fiscal policy instruments decrease final good demand by reducing 
Table 3 Unit root tests

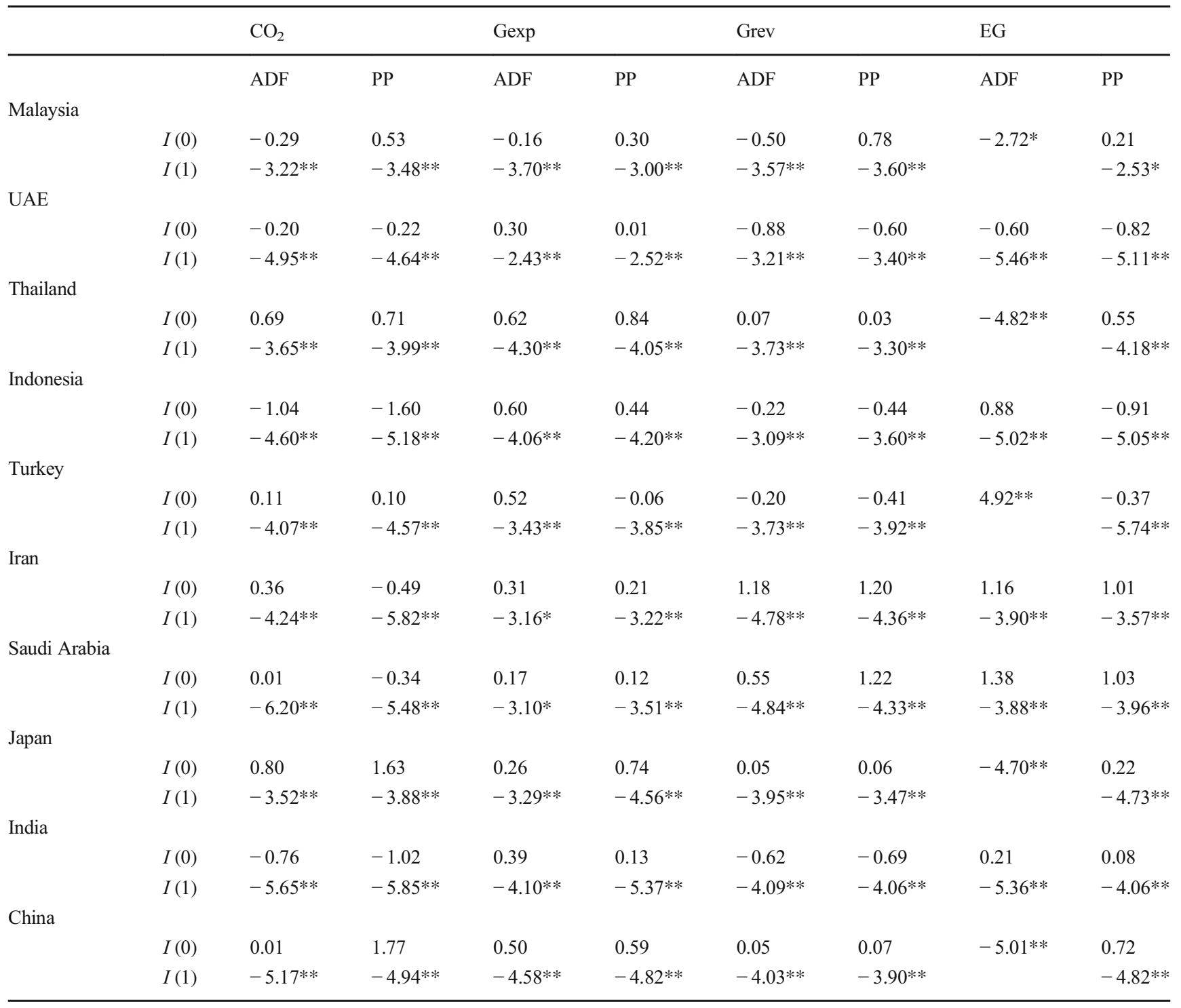

$*$ and $* *$ indicate significance levels at $10 \%$ and $5 \%$, respectively

government expenditure and household consumption, in adverse, achieve the environmental quality in Asian economies except for Japan. The Japanese economy has to endure environmental loss as negative shocks in government expenditures result in an increase in carbon dioxide by $0.178 \%$. In contrast, the climate of two economies, i.e., Saudi Arabia and China, show no association with the negative shocks. The results also show that a positive shock of government spending is more effective in the environment in magnitude compared to a negative shock.

Furthermore, the positive shocks in government revenues show a positive association with pollution in 8 out of 10 economies. It implies that $1 \%$ increase in government revenues causes to emit $\mathrm{CO}_{2}$ by $0.281 \%$ in Malaysia, $0.043 \%$ in UAE, $0.226 \%$ in Thailand, $0.236 \%$ in Indonesia, $0.266 \%$ in
Turkey, $0.138 \%$ in Iran, $0.208 \%$ in India, and $0.207 \%$ in China. The possible reason is that the increasing ratio of taxes to generate the revenues forces the producers to use traditional methods of production. These production methods require fossil fuel based-energy intensively, as a result, $\mathrm{CO}_{2}$ emissions rise in these economies. Also, higher government income levels, which are usually linked with increased government spending, enhance the public infrastructure that is not better for environmental quality. This finding is consistent with Yuelan et al. (2019), who noted that government revenue initially increases environmental pollution. A positive government revenue shock improves consumption and increases carbon pollution. In contrast, the economy of Japan gains environmental advantages since the upward trend in government revenues contracts the ratio of $\mathrm{CO}_{2}$ emissions. 
Table 4 Zivot-Andrews unit root tests

$\begin{array}{llll}\mathrm{CO}_{2} & \mathrm{Gexp} & \mathrm{Grev} & \mathrm{EG}\end{array}$

\begin{tabular}{|c|c|c|c|c|c|}
\hline \multicolumn{6}{|l|}{ Malaysia } \\
\hline & $I(0)$ & -3.265 & -3.439 & -4.434 & $-6.307 * * *$ \\
\hline & Break year & 2003 & 1987 & 2006 & 1998 \\
\hline & $I(1)$ & $-6.953 * * *$ & $-6.934 * * *$ & $-6.701 * * *$ & $-7.523 * * *$ \\
\hline & Break year & 1989 & 1999 & 2001 & 1997 \\
\hline \multicolumn{6}{|l|}{ UAE } \\
\hline & $I(0)$ & -3.927 & -4.238 & -4.225 & $-7.119 * * *$ \\
\hline & Break year & 2006 & 2012 & 1991 & 1989 \\
\hline & $I(1)$ & $-9.035^{* * * *}$ & $-5.106^{* *}$ & $-4.913 *$ & $-7.456 * * *$ \\
\hline & Break year & 1998 & 1991 & 1999 & 1991 \\
\hline \multicolumn{6}{|l|}{ Thailand } \\
\hline & $\begin{array}{l}I(0) \\
\text { Break year }\end{array}$ & $\begin{array}{l}-2.595 \\
1993\end{array}$ & $\begin{array}{l}-3.183 \\
2007\end{array}$ & $\begin{array}{l}-5.059^{* *} \\
1998\end{array}$ & $\begin{array}{l}-4.489 \\
1996\end{array}$ \\
\hline & $I(1)$ & $-6.322 * * *$ & -4.555 & $-7.867 * * *$ & $-8.532 * * *$ \\
\hline & Break year & 1988 & 1992 & 2001 & 1999 \\
\hline \multicolumn{6}{|l|}{ Indonesia } \\
\hline & $I(0)$ & -3.158 & -2.995 & $-5.501 * * *$ & $-6.054 * * *$ \\
\hline & Break year & 2007 & 1987 & 1999 & 1998 \\
\hline & $I(1)$ & $-6.780 * * *$ & $-7.273^{* * *}$ & $-8.712 * * *$ & $-7.197 * * *$ \\
\hline & Break year & 2012 & 2001 & 2009 & 2000 \\
\hline \multicolumn{6}{|l|}{ Turkey } \\
\hline & ADF test & -3.590 & $-5.321 * *$ & $-7.500 * * *$ & $-6.936^{* * *}$ \\
\hline & $I(0)$ & 2006 & 1990 & 2008 & 2003 \\
\hline & Break year & & & & \\
\hline & $I(1)$ & $-7.413 * * *$ & $-6.366^{* * *}$ & $-6.295 * * *$ & $-7.138 * * *$ \\
\hline & Break year & 2012 & 1989 & 2010 & 2002 \\
\hline \multicolumn{6}{|l|}{ Iran } \\
\hline & $I(0)$ & -2.739 & -4.415 & -3.181 & $-5.921 * * *$ \\
\hline & Break year & 1999 & 1989 & 2010 & 1989 \\
\hline & $I(1)$ & $-7.129 * * *$ & $-5.685^{* * * *}$ & $-7.036^{* * * *}$ & $-10.89 * * *$ \\
\hline & Break year & 1998 & 1993 & 2007 & 1998 \\
\hline \multicolumn{6}{|c|}{ Saudi Arabia } \\
\hline & $I(0)$ & -3.878 & $-4.867 *$ & -3.244 & -3.211 \\
\hline & Break year & 1995 & 2012 & 1999 & 1998 \\
\hline & $I(1)$ & $-8.755^{* * *}$ & $-7.458^{* * * *}$ & -3.985 & $-13.32 * * *$ \\
\hline & Break year & 2000 & 1998 & 2012 & 1992 \\
\hline \multicolumn{6}{|l|}{ Japan } \\
\hline & $I(0)$ & -2.973 & -4.171 & -4.007 & $-6.323 * * *$ \\
\hline & Break year & 2005 & 2005 & 1998 & 1992 \\
\hline & $I(1)$ & $-7.411 * * *$ & $-5.336^{* *}$ & $-5.740 * * *$ & $-6.983 * * *$ \\
\hline & Break year & 2010 & 1992 & 1992 & 2010 \\
\hline \multicolumn{6}{|l|}{ India } \\
\hline & $I(0)$ & -3.013 & -3.018 & -3.748 & $-5.167 * *$ \\
\hline & Break year & 2007 & 2005 & 2002 & 2011 \\
\hline & $I(1)$ & $-7.170^{* * *}$ & $-4.659 *$ & $-7.192 * * *$ & $-5.759 * * *$ \\
\hline & Break year & 2012 & 1998 & 1990 & 2007 \\
\hline \multicolumn{6}{|l|}{ China } \\
\hline & $I(0)$ & -2.872 & $-4.733^{*}$ & -2.665 & $-4.717 *$ \\
\hline & Break year & 2005 & 2006 & 1989 & 2011 \\
\hline & $I(1)$ & $-5.721 * * *$ & -4.325 & $-9.954 * * *$ & $-6.067 * * *$ \\
\hline & Break year & 2012 & 2011 & 2008 & 1991 \\
\hline
\end{tabular}

The $10 \%, 5 \%$, and $1 \%$ critical values are $-4.58,-4.93$, and -5.34

The negative shocks in government revenues, in contrast, ameliorate the deleterious repercussions of pollution in 6 of concerned economies. It signifies that carbon emissions decline on account of a downward trend in government revenues by $0.100 \%$ in Malaysia, $0.008 \%$ in UAE, $0.115 \%$ in Thailand, $0.154 \%$ in Indonesia, $0.012 \%$ in Iran, and $0.083 \%$ China. Only the Japanese economy enjoys the environmental benefits as negative shocks in government revenue decrease the amount of $\mathrm{CO}_{2}$ by $0.095 \%$. Also, 3 countries exhibit no response to the negative shocks, and these countries are Turkey, Saudi Arabia, and India. Moreover, a lower government income tax revenue uniquely decreases the government's spending that reduces carbon emissions. With lower government revenues, the emission level responds less to the government spending negative shock; therefore, it is easier for the management to maintain the carbon emissions target. We also 


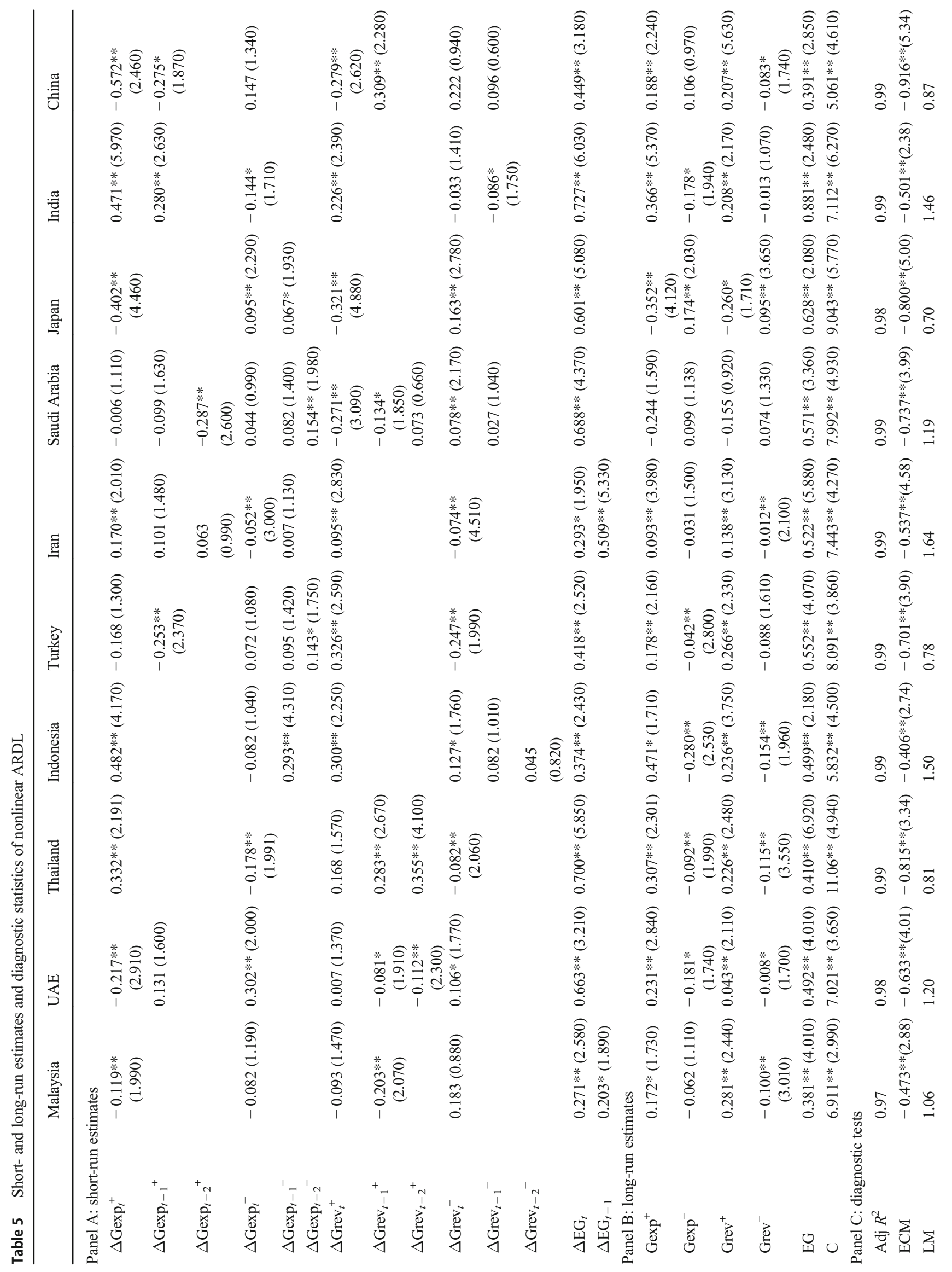


suggested that increasing fiscal revenues with affecting its public spending structure is not neutral for the environment in Asian economies. Again, all the economies demonstrate the consensus on the unfriendly environmental effects of GDP growth on account of surging carbon emissions in the long run.

Beyond that, we report the outcomes of some diagnostic tests in panel C. The results also conclude that $\mathrm{ECM}_{t-1}$ statistics of all sampled economies are significantly negative. It indicates that the adjustment rate towards the long-run equilibrium is $47 \%$ in Malaysia, $63 \%$ in UAE, $81 \%$ in Thailand, $40 \%$ in Indonesia, $70 \%$ in Turkey, $53 \%$ in Iran, $73 \%$ in Saudi Arabia, $80 \%$ in Japan, 50\% in India, and 91\% in China. The LM and LM test with the structural break and RESET tests are also deployed to determine the autocorrelation and model specification, respectively. The findings suggest that all models of the selected sample are robust as the statistics of the LM and RESET tests are insignificant. To check the stability of the NARDL estimates, we apply CUSUM and CUSUMQ tests that confirm the stability of the parameters of most models. Besides, the values of adjusted $R^{2}$ report the goodness of fit of models. The short- and long-run asymmetries are further supported by the Wald test of fiscal policy instruments. The results show that short- and long-run asymmetries exist in both variables in some selected economies. The asymmetry curves show the nonlinear mixture of the dynamic multipliers due to positive and negative shocks of the government expenditure and revenue variables (Fig. 1).

\section{Conclusion and policy implications}

Fiscal policy instruments are said to have positive or negative effects on environmental quality, depending on the public sector spending and tax revenues. However, due to changes in their expectations, the impacts of fiscal policy instruments on the environment could be asymmetric. Therefore, the study examines the asymmetric effects of fiscal policy instruments on environmental pollution by using the NARDL approaches for a dataset covering the 1980-2018 period for Malaysia, UAE, Thailand, Indonesia, Turkey, Iran, Saudi Arabia, Japan, India, and China.

The outcome of asymmetric ARDL exhibits that positive shock of government expenditure has a positive effect on the environmental pollution in the proposed economies, including Malaysia, UAE, Thailand, Indonesia, Turkey, Iran, India, and China. However, the adverse shocks decline the carbon pollution in these economies. While Japan gets environmental improvements through the decline in carbon emissions when the government expenditure trends to increases over time. While the Japanese government expenditure negative shocks also have a positive influence on carbon emissions. Our results have revealed that the positive shock of government 
Malaysia
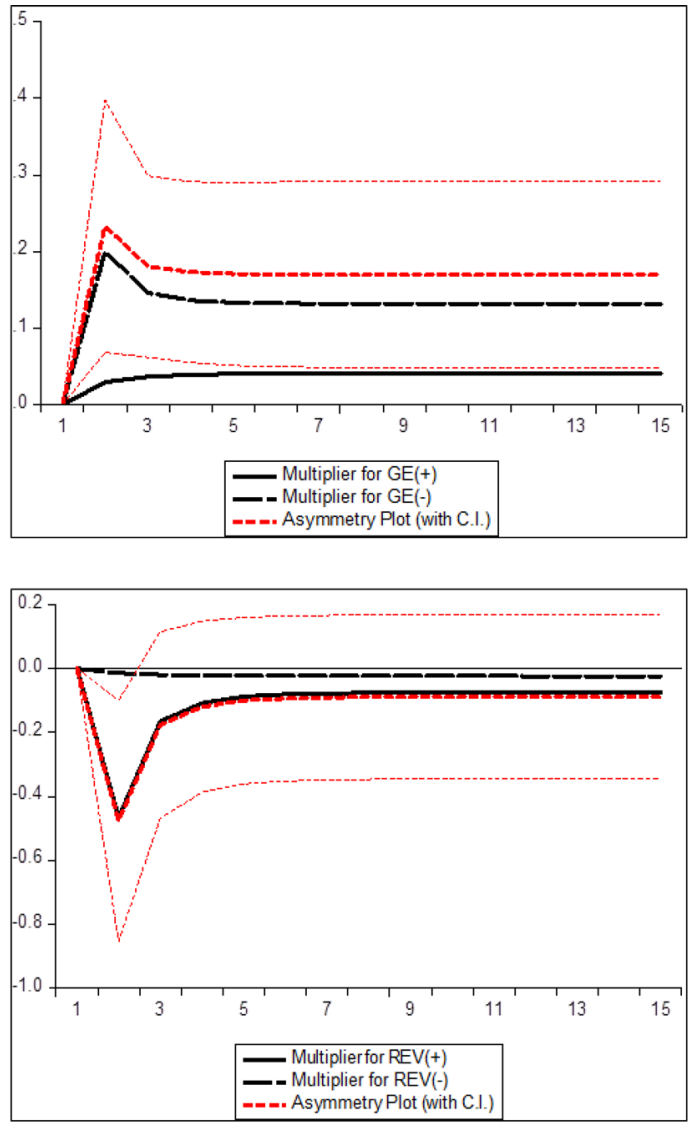

UAE
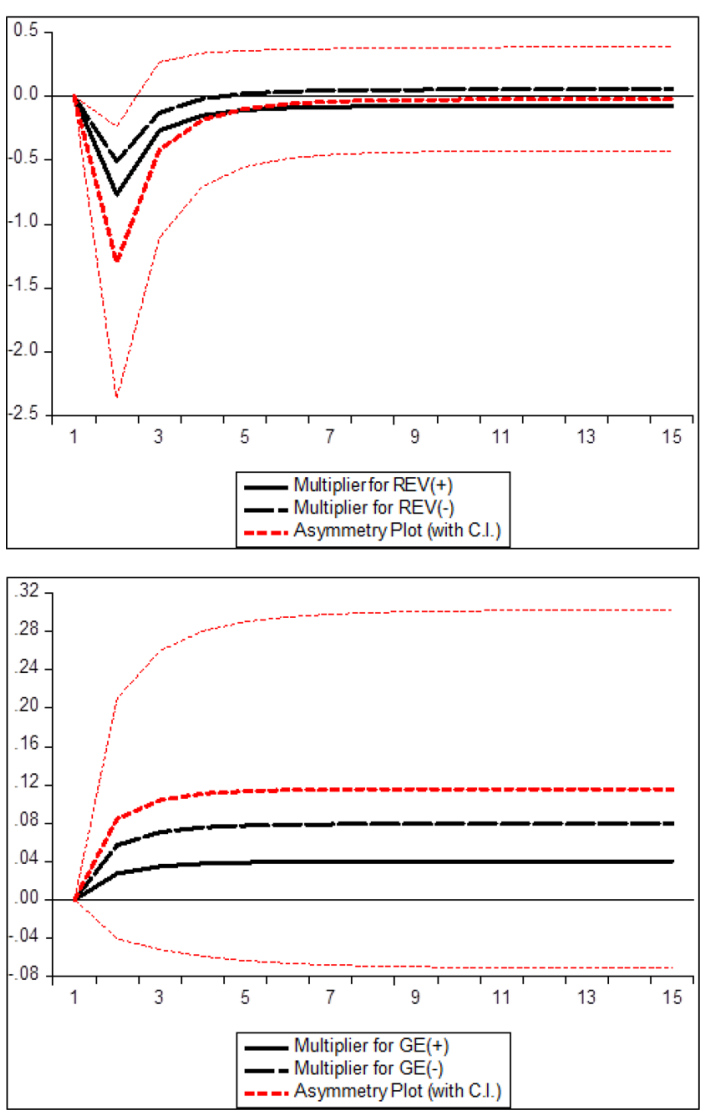

Fig. 1 Dynamic multiplier graphs of Asian economies. GE is government expenditure and REV is government revenues. Years are plotted on the horizontal axis and the magnitude shocks (+ and - ) on the vertical axis

revenue enhances the environmental pollution of eight countries (Malaysia, UAE, Thailand, Indonesia, Turkey, Iran, India, and China). In contrast, the negative shocks of government revenues carry favorable impacts on the environment quality of these eight economies. While the Japanese government's positive and negative shocks in revenues have similar results on environments as in the case of government expenditure, the findings also revealed that government expenditure outcomes are also maintained in Malaysia, UAE, Thailand, Indonesia, Turkey, Iran, India, and China, means that a lower (higher) government income tax revenue uniquely decreases (increase) the government's spending that reduces (increase) the carbon emissions. However, fiscal policy instruments in Saudi Arabia's economy have an insignificant influence on environmental pollution. Overall, the asymmetric findings are also country-specific, and in general, carbon pollution could be attributed to fiscal policy phenomena in the proposed economies.

Based on these findings, regarding public spending, Asian economics should devote revenues to green public goods which are completely environmental-friendly. By awareness of private consumption, Asian economies should motivate households and firms to use those methods and tools which are environmentally friendly in household consumption, firms production method, and transportations. The Asian economies should minimize the carbon emissions through fiscal policy instruments as well as monetary policy because fiscal policy is not a specific solution. At the time of fiscal policy, Asian economies set up long-term environmental policies by considering the government expenditure and revenue. Fiscal policies must be independent in Asian economies because efficient fiscal policies can help to minimize environmental pollution. Asian economies should introduce green energy in public transportation and physical capital that is normally small carbon emitters. In sum, the importance of fiscal policies is strongly emphasized further in the context of climate change. Public spending will be increased sharply in many countries during previous years in response to the coronavirus that Asian economies must consider environmental quality. The governments in the Asian region need to heavily invest in human capital, offer concessional bank lending to green economic activities, increase clean infrastructure investment and provide tax incentives to capital markets, and increase consumer financing so that technical and market barriers are sufficiently eased. Households, especially the poor ones and producers who are more carbon emitters, will need some sort of support to assistance from fiscal policy instruments. Also, the 
Thailand
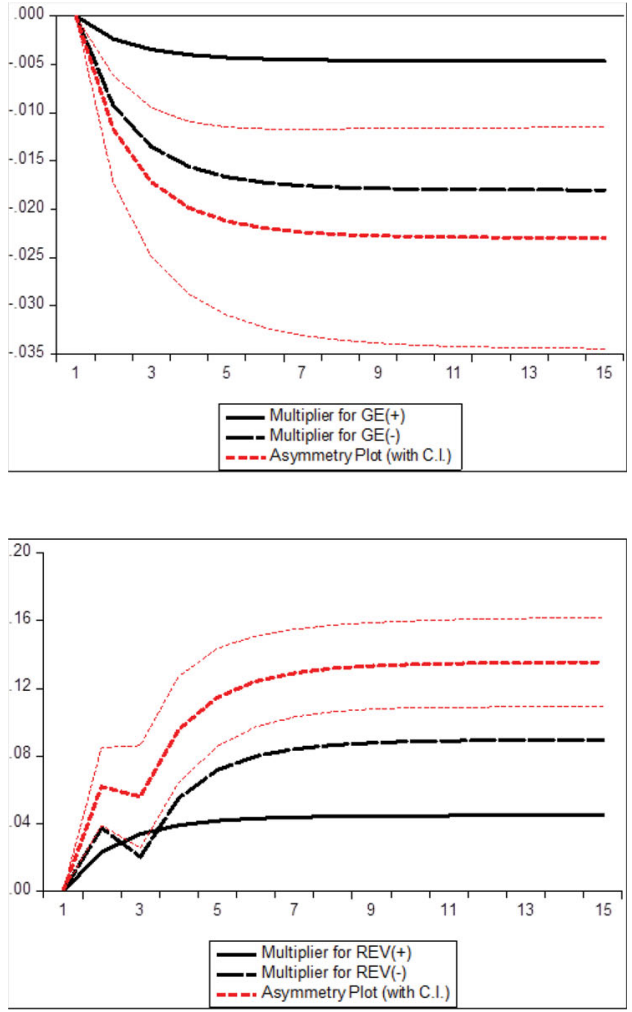

Indonesia
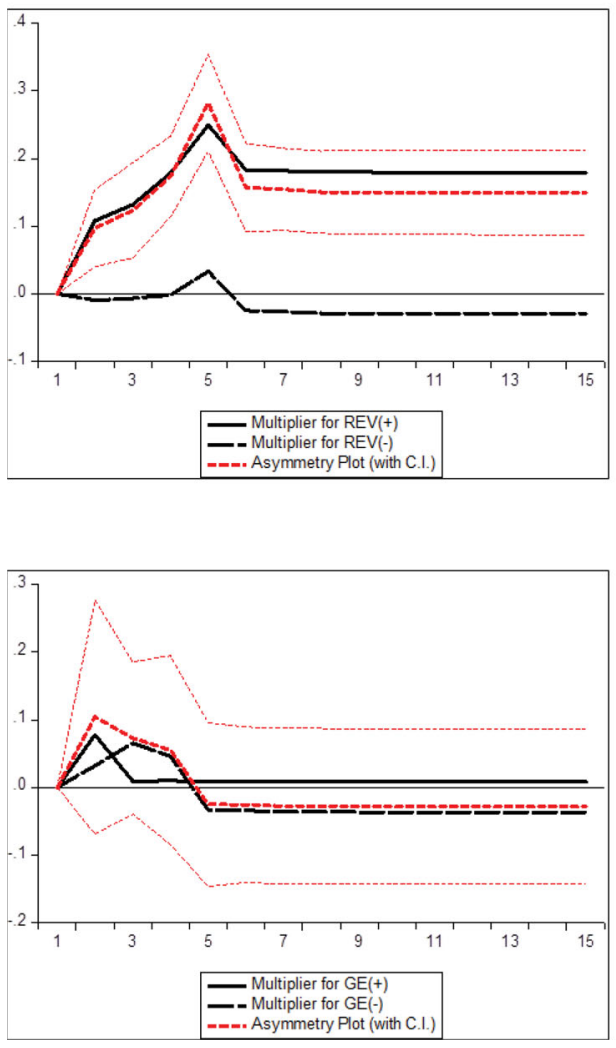

Fig. 1 continued.
Turkey
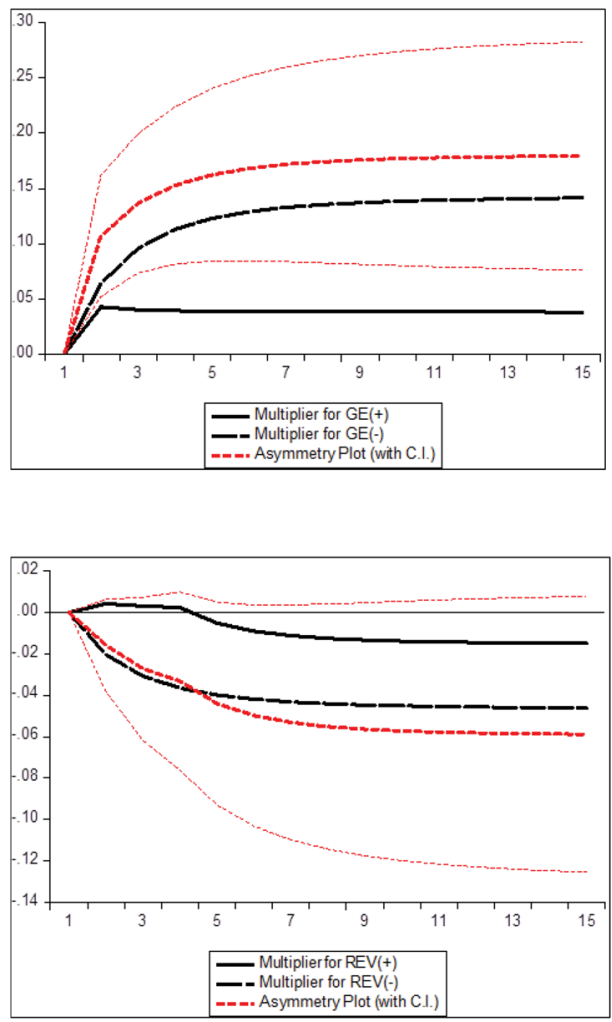

Iran
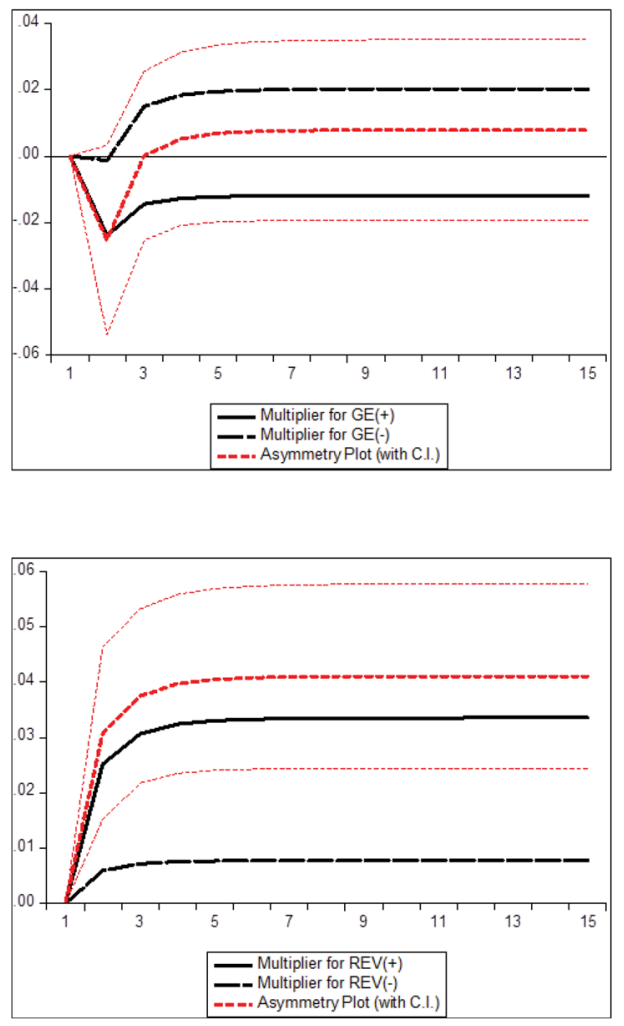

Fig. 1 continued. 


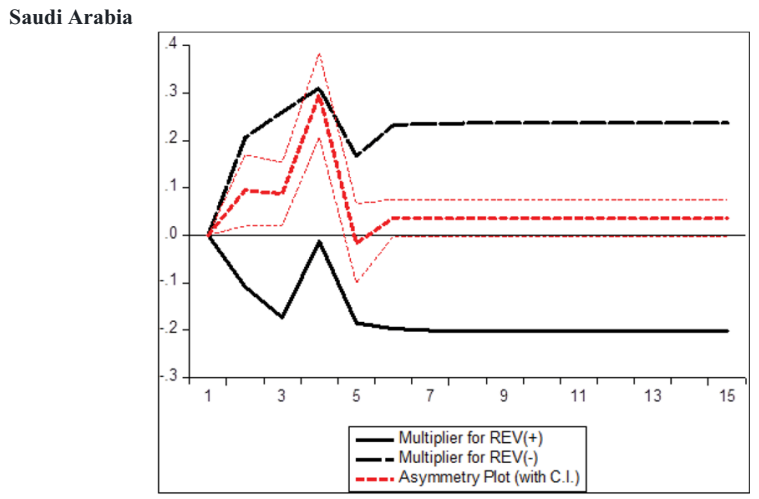

India
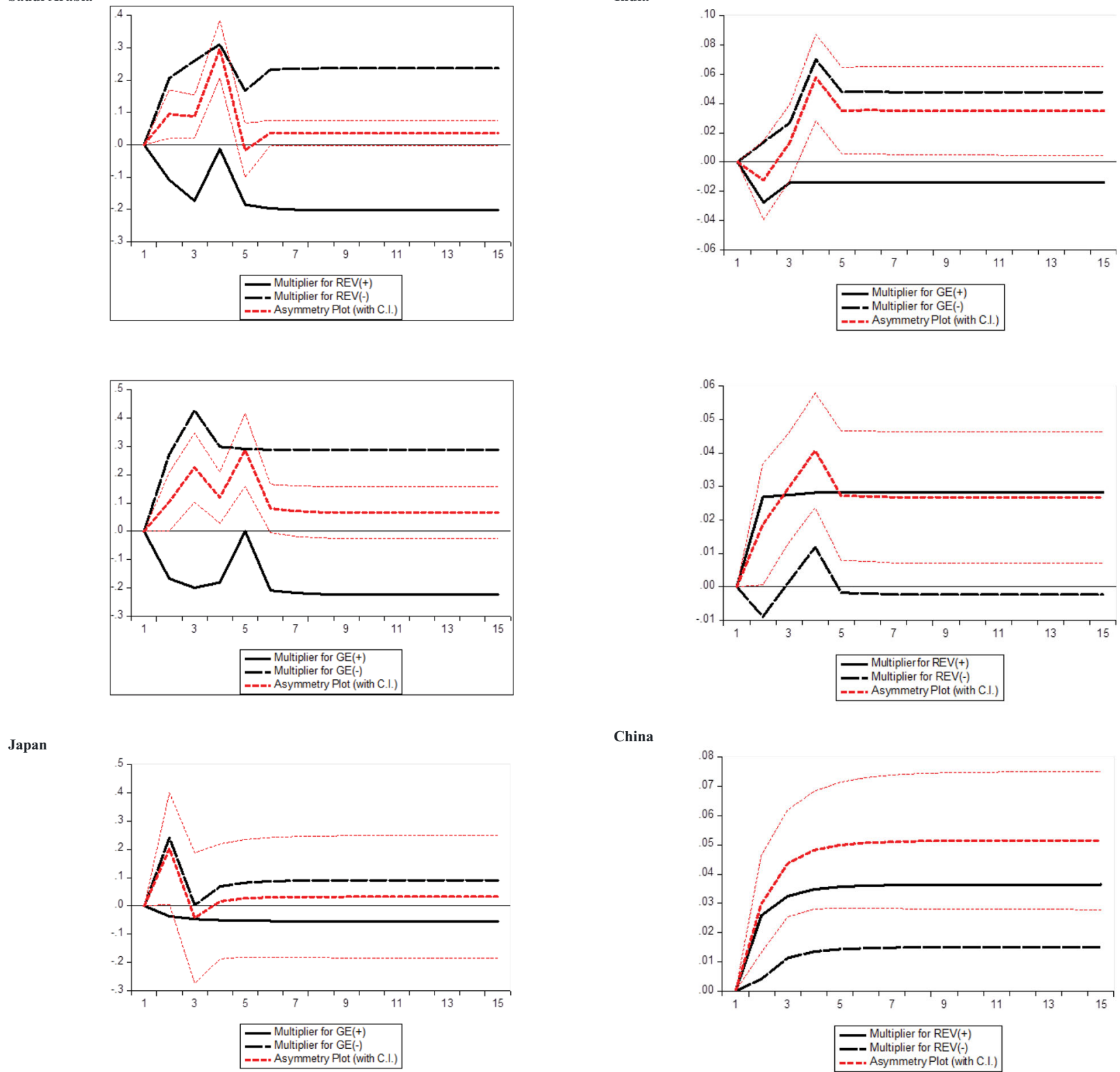

China
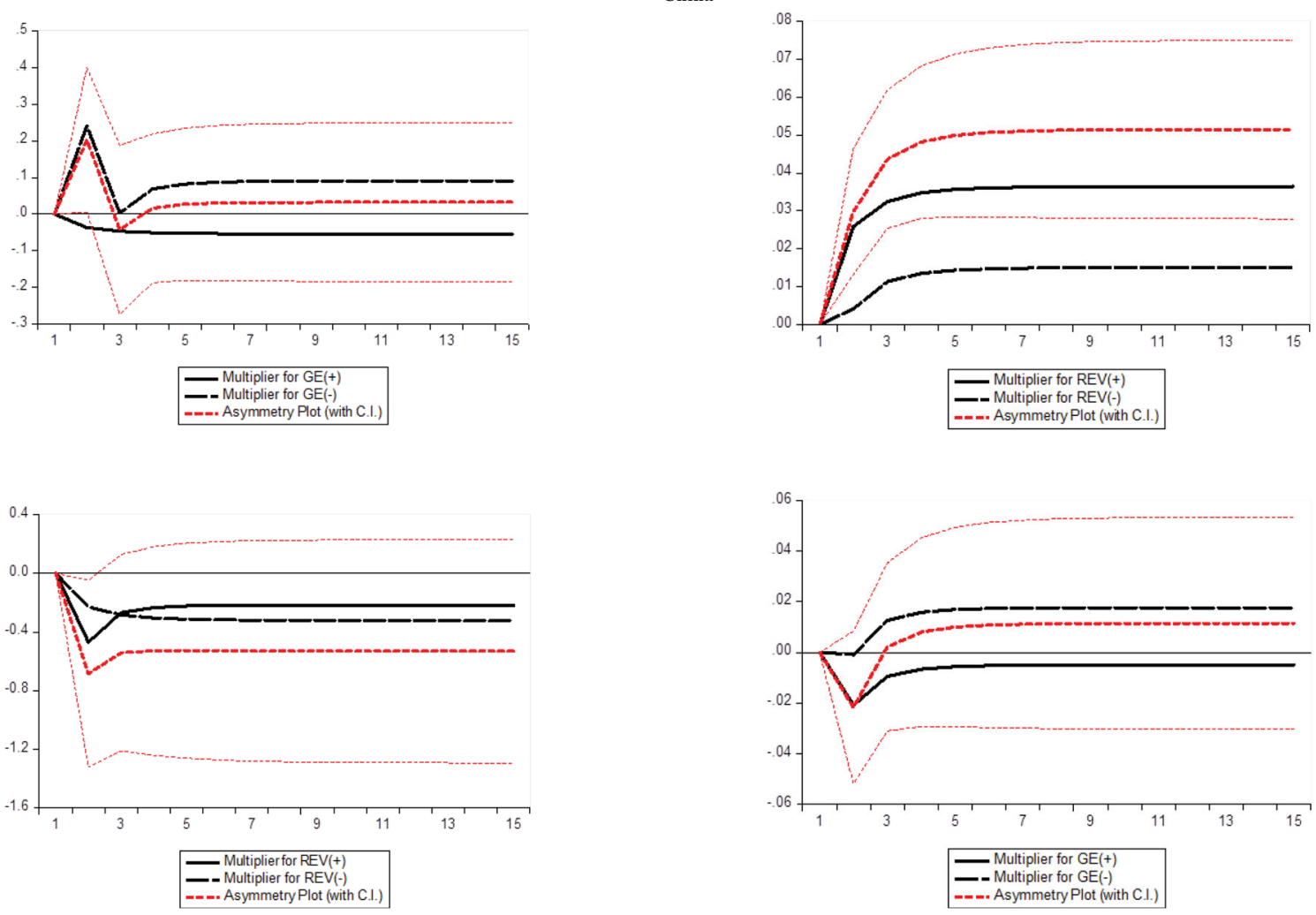

Fig. 1 continued.

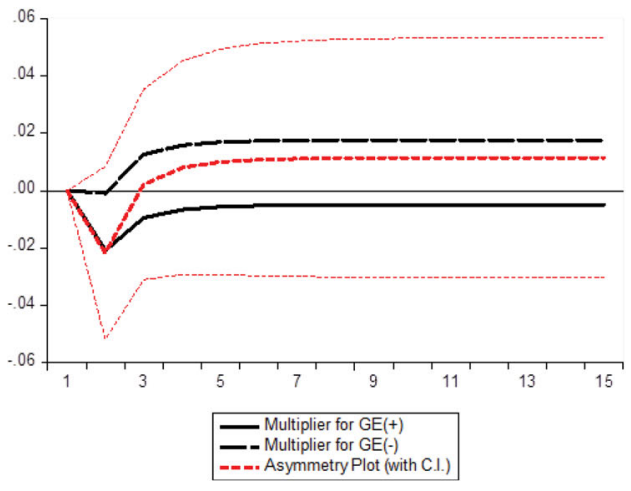

Fig. 1 continued. 
Japanese government should maintain the emphasis on public spending on human capital goods leads to a greater reduction of carbon emissions than aggregate spending, for both consumption- and production-generated emissions. For policy implications, our results also highlight the importance of policy coordination.

\section{References}

Asian Development Bank (ADB) (2011) Key indicators for Asia and the Pacific. Asian Development Bank, Manila

Bahmani-Oskooee M, Usman A, Ullah S (2019) Asymmetric J-curve in the commodity trade between Pakistan and United States: evidence from 41 industries. Eur Econ Rev:1-26

Bernauer, T., \& Koubi, V (2006) States as providers of public goods: how does government size affect environmental quality?. Available at SSRN 900487

Chan YT (2020) Are macroeconomic policies better in curbing air pollution than environmental policies? A DSGE approach with carbondependent fiscal and monetary policies. Energy Policy 141:111454 111468

Chaturvedi A, Saluja MS, Banerjee A, Arora R (2014) Environmental fiscal reforms. IIMB Manag Rev 26(3):193-205

Dulal HB, Dulal R, Yadav PK (2015) Delivering green economy in Asia: the role of fiscal instruments. Futures 73:61-77

Frederik C, Lundström S (2001) Political and economic freedom and the environment: the case of $\mathrm{CO} 2$ emissions. Working paper no. 29. Department of Economics, Göteborg University
Gerlagh R, Van Den Bijgaart I, Nijland H, Michielsen T (2018) Fiscal policy and $\mathrm{CO} 2$ emissions of new passenger cars in the EU. Environ Resour Econ 69(1):103-134

Halkos GE, Paizanos EA (2013) The effect of government expenditure on the environment: an empirical investigation. Ecol Econ 91:48-56

Halkos GE, Paizanos EA (2016) The effects of fiscal policy on CO2 emissions: evidence from the USA. Energy Policy 88:317-328

International Energy Agency (2012) Analysis of the globally installed coal-fired power plant Fleet. IEA, Paris

Katircioglu S, Katircioglu S (2018) Testing the role of fiscal policy in the environmental degradation: the case of Turkey. Environ Sci Pollut Res 25(6):5616-5630

Lopez, R. E., \& Palacios, A. (2010). Have government spending and energy tax policies contributed to make Europe environmentally cleaner? (No. 1667-2016-136345)

López R, Galinato GI, Islam A (2011) Fiscal spending and the environment: theory and empirics. J Environ Econ Manag 62(2):180-198

Narayan PK (2005) The saving and investment nexus for China: evidence from cointegration tests. Appl Econ 37:1979-1990

Pesaran MH, Shin Y, Smith RJ (2001) Bounds testing approaches to the analysis of level relationships. J Appl Econ 16(3):289-326

Shin Y, Yu B, Greenwood-Nimmo M (2014) Modelling asymmetric cointegration and dynamic multipliers in a nonlinear ARDL framework. In: Festschrift in honor of Peter Schmidt. Springer, New York, pp 281-314

World Bank (2020) World development indicators 2020. World Bank Publications

Yuelan P, Akbar MW, Hafeez M, Ahmad M, Zia Z, Ullah S (2019) The nexus of fiscal policy instruments and environmental degradation in China. Environ Sci Pollut Res 26(28):28919-28932

Publisher's note Springer Nature remains neutral with regard to jurisdictional claims in published maps and institutional affiliations. 